\title{
The Impact of the American Academy of Ophthalmology's Leadership Development Program: Experience from the First 20 Years
}

\author{
Linda M. Tsai, MD ${ }^{1}$ Holly A. Schroth, PhD ${ }^{2}$ Gail E. Schmidt ${ }^{3}$ Paul Sternberg Jr, MD ${ }^{4}$
}

${ }^{1}$ John F. Hardesty MD Department of Ophthalmology and Visual Sciences, Washington University in St. Louis, St. Louis, Missouri

2 Management of Organization, Haas Berkeley School of Business, Berkeley, California

${ }^{3}$ Department of Ophthalmic Relations, American Academy of Ophthalmology, San Francisco, California

${ }^{4}$ Vanderbilt Eye Institute, Vanderbilt University Medical Center,

Nashville, Tennessee

\begin{abstract}
Address for correspondence John F. Hardesty, MD, John F. Hardesty MD Department of Ophthalmology and Visual Sciences, Washington University in St. Louis, 660 Street Euclid Avenue, Box 8096, St. Louis, MO 63110 (e-mail: tsai@wustl.edu).
\end{abstract}

J Acad Ophthalmol 2021;13:e138-e143.

Abstract

Keywords
- leadership
- LDP program
- American Academy of
Ophthalmology
- Likert scale
- survey
- self-efficacy
- confidence
- motivation
- gender diversity

Objective This study aimed to analyze the effectiveness of the American Academy of Ophthalmology (AAO)'s Leadership Development Program (LDP), report the program's impact on participants in attaining ophthalmic leadership positions, and identify opportunities to improve future LDP programming.

Design An open cohort study was performed on AAO LDP graduates by using an online questionnaire and retrospective monitoring.

Participants and Methods AAO LDP graduates from 1999 to 2019 participated in the study. A Likert-scale survey was distributed via email. Online responses were submitted anonymously to a team at the Berkeley Haas School of Business for analysis. A separate review of gender demographics and ophthalmic leadership positions held by graduates was performed.

Main Outcomes Measures Regression analysis was performed to determine whether survey results supported a meaningful relationship between the measured impact and the AAO LDP program's perceived effectiveness. Ascension into leadership positions of AAO-related organizations at the national, regional, state, and subspecialty level by AAO LDP graduates was collated.

Results Of 381 potential respondents, 203 survey responses were returned (53.3\%). 158 reported that they are currently holding a leadership position (77.8\%). Statistical analyses indicated that the overall value of the program was seen as highly effective $(M=4.6)$, and that the development programs combined contributed significantly to AAO LDP being judged as effective overall, $\mathrm{F}(11,191)=24.79 ; p<0.001$ with an $R^{2}$ of 0.59 . Longitudinal tracking of the 383 graduates revealed that $268(70.0 \%)$ have served as AAO committee/task force members, councilors, or representatives to outside organizations. A total of $242(63.2 \%)$ graduates have served as president or chair of a received

February 22, 2021 accepted after revision June 22, 2021
DOI https://doi.org/ $10.1055 / \mathrm{s}-0041-1735954$ ISSN 2475-4757.

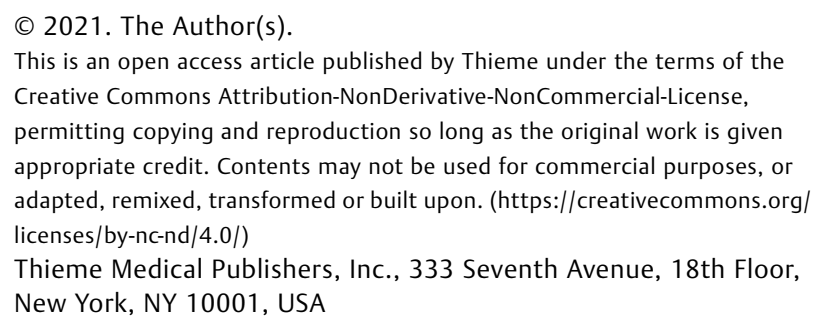
appropriate credit. Contents may not be used for commercial purposes, or adapted, remixed, transformed or built upon. (https://creativecommons.org/ licenses/by-nc-nd/4.0/) Thieme Medical Publishers, Inc., 333 Seventh Avenue, 18th Floor, New York, NY 10001, USA 
state, subspecialty, or specialized interest ophthalmology society. 25 (6.5\%) have served at the highest level of AAO leadership and two have been elected AAO President. A higher percentage of participants identifying as female was found in the LDP program compared with both U.S. overall and trainee ophthalmic populations. Conclusion The AAO LDP has fulfilled its initial goals of effectively developing a large cohort of ophthalmologists interested in and prepared to take on leadership roles across the profession. Development of more specific outcome measures to evaluate the program, as well as direct optimal programming, are needed to further the success of its aims.

The American Academy of Ophthalmology (AAO) is the world's largest association of eye surgeons and physicians. Its mission is to protect sight and empower lives by serving as an advocate for patients and the public, leading ophthalmic education, and advancing the profession of ophthalmology. ${ }^{1}$ As with all organizations with similar missions, the Academy has recognized the need for there to be a steady bench of future leaders for positions of leadership at the state and national levels. To assist in achieving this goal, Michael W. Brennan, MD and Paul Sternberg Jr., MD founded the AAO Leadership Development Program (LDP) in 1998 with the assumption that future leaders are made, not born to the role. The AAO LDP program was designed to include elements of mentoring, organizational education, skills training, and guided experiences to cover the three "P's" of leadership: the philosophy of leadership; the principles of leadership, and the practice of leadership as they relate to state, subspecialty, and specialized interest societies, as well as to the AAO organization as a whole. ${ }^{2}$

The AAO LDP program is limited to no more than 20 ophthalmologist participants each year, competitively selected from nominating state, subspecialty, and specialized interest organizations in ophthalmology. The selected participants are required to attend four sessions of structured programming over 12 months, and they are paired with a mentor to help them identify and implement a project designed to help their nominating organization. Starting in 2003, one slot in each class was held for an international participant. For their required project, several of these international participants were encouraged to develop complementary leadership development programs for their region of the globe with the support of AAO LDP leaders and staff. Care has been taken by the AAO's Director of Ophthalmic Society Relations to maintain relationships with LDP graduates. Newsletters are published at regular intervals, recognizing, and spotlighting leadership achievements of past graduates. Global LDP alumni receptions have also been implemented to create a sense of community and foster encouragement of international advancements of common ophthalmic interests.

LDPs are often evaluated based on some version of Kirkpatrick's four level tool for the evaluation of training programs, ${ }^{3}$ which looks at subjective or objective out- come measures of reaction, learning, behavior, and results. The value of leadership training in ophthalmology, where it benefits the profession across clinical, educational, and organizational levels, has been discussed previously in an article by Green et al. ${ }^{4}$ With more than two decades of AAO LDP graduates, the intention of this study is to evaluate the impact of this initiative via two different methods: (1) an online survey developed to measure former participants' perception of program effectiveness, and (2) a retrospective review of leadership positions held by LDP graduates concurrent to and after completion of the program.

In the evaluation of AAO LDP program, we propose the hypothesis that professional development leadership training will increase self-efficacy, which in turn will raise participants' self-confidence that they have obtained leadership skills. In addition, the increase in self-efficacy will increase motivation to take a leadership position in the organization. Several studies (Klassen et al, Metso et al, and Petridou et al) indicate a strong relationship between professional development training and self-efficacy. ${ }^{5-7}$ Self-efficacy beliefs are the expectations that people hold about their abilities to accomplish certain tasks. ${ }^{8}$ People will strive to perform particular tasks or attempt to achieve specific goals depending on whether they believe they have the ability to succeed. Those with high self-efficacy are more likely to try harder to master a challenge than those with low self-efficacy, and will also increase their engagement in tasks further raising their performance and subsequent self-efficacy beliefs. ${ }^{9,10}$ According to Bandura, ${ }^{11}$ professional development can raise confidence in one's ability to achieve desired skills through verbal persuasion (motivational speakers), vicarious modeling (mentorship), and enactive mastery where one gains confidence through relevant experiences (cases, exercises, and projects). Increasing self-efficacy has been found to increase motivation, job involvement, and commitment to the organization. ${ }^{12}$ The expected impact of professional development leadership training is that it will increase selfefficacy. This increase in self-efficacy raises participants' self-confidence that they have obtained leadership skills, and that they will have a motivation to take a leadership position in the organization. 


\section{Participants and Methods}

A team from the Haas School of Business, University of California, Berkeley was recruited to collect primary data through a Google forms questionnaire that it developed based on a semi- structured interview with the AAO LDP Director and the AAO Director of Ophthalmic Society Relations, LDP course material, and theoretical based expectations. Institutional review board/ethics committee ruled that approval was not required for this study and all work adhered to the Declaration of Helsinki and all federal and state laws in the United States.

The survey was distributed to LDP graduates since program inception through the class of 2019. Surveys were sent to 381 potential respondents. Results were collated and analyzed by the team from UC Berkeley. The survey measured demographic information such as gender and years in the program, and it was comprised of 17 statements on a 5point Likert-scale $(1=$ strongly disagree and $5=$ strongly agree). In total, 11 statements measured the respondents' perceived improvement of a leadership skill taught in the LDP workshops. Examples of these items include "I improved my public speaking skills" and "I improved my negotiation skills." Four statements measured motivation to take on more leadership responsibility after having attended the LDP workshops (e.g., "I was motivated to seek more leadership responsibility" and "I actively pursued a leadership position after attending the program"). The two dependent measures assessed whether they gained confidence in their own leadership skills after attending the LDP workshops and their perceptions of the overall effectiveness of the LDP program. Results were analyzed by using both descriptive statistical and regression analyses. Of the first 20 years of participants who attended the program between 1998 and 2019, it can be assumed that some have retired, and two are known to be deceased. Out of 381 potential respondents, 203 (53.3\%) anonymous responses were received: 126 (62.1\%) were males, 75 (36.9\%) females, and 2 (1\%) preferred not to say. Current age ranges were from 34 to 78 years old. However, 158 respondents (77.8\%) answered "yes" when asked, "are you currently in a leadership position?"

With regard to confidence in the skills promoted in the AAO LDP curriculum, - Table 1 shows the means and standard deviations of the participants' perceived improvement of a leadership skill taught in the LDP workshops. The workshops on political advocacy, networking, and public speaking led to the most improvement of a leadership skill, whereas managing antitrust issues and handling fiduciary responsibilities were scored as less effective.

Results of two-tailed $t$-tests on means comparing men's and women's perceived effectiveness of the LDP workshops had indicated two significant differences. Women indicated a greater improvement from skills training to work in teams $(\mathrm{M}=4.29$, standard deviation $[S D]=0.45)$ than men $(\mathrm{M}=4.02, \mathrm{SD}=0.95), t[196]=1.97, p<0.001)$, and women had a greater improvement in their public speaking skills $(\mathrm{M}=4.41, \mathrm{SD}=0.51)$ than men $(\mathrm{M}=4.1, \mathrm{SD}=0.69) t$ $[173]=1.97, p<0.001)$.
Table 1 Means and standard deviations for effectiveness of Leadership Development Program workshops

\begin{tabular}{|l|l|l|}
\hline Workshop & Mean & $\begin{array}{l}\text { Standard } \\
\text { deviation }\end{array}$ \\
\hline Negotiation & 4.0 & 0.91 \\
\hline Delegation & 3.96 & 0.87 \\
\hline Media relations & 4.19 & 0.86 \\
\hline Political advocacy & 4.5 & 0.69 \\
\hline Antitrust issues & 3.3 & 1.01 \\
\hline Run meeting & 4.16 & 0.88 \\
\hline Public speaking & 4.23 & 0.8 \\
\hline Networking & 4.42 & 0.78 \\
\hline Team work & 4.12 & 0.85 \\
\hline $\begin{array}{l}\text { Handle fiduciary } \\
\text { responsibilities }\end{array}$ & 3.60 & 1.01 \\
\hline $\begin{array}{l}\text { Communicated with } \\
\text { international colleagues }\end{array}$ & 3.88 & 1.02 \\
\hline
\end{tabular}

- Table 2 shows the means and standard deviations of the participants' motivation to take on more leadership after having attended the AAO LDP workshops. All participants were motivated to take on more leadership roles after having attended the LDP workshops.

Regression analyses on the data indicated that the development programs combined contributed significantly to AAO LDP being judged as effective overall $(F[11,191)=24.79, p$ $<0.001$ with an $R^{2}$ of 0.59 ), and that the development programs combined contributed significantly to their confidence in their leadership skills $(\mathrm{F}[11,191]=18.95, p<0.001$ with an $R^{2}$ of 0.52 ). When sorting based on whether someone currently held a leadership position, the overall value of the development program to the effectiveness of the program increased ( $F$ $[11,146]=22.67, p<0.001$ with an $R^{2}$ of 0.63 ).

Additional regression analyses examined the contribution of each workshop skill to the AAO LDP's overall perceived effectiveness. Results indicate the program on networking skill $\left(\mathrm{F}[1,201]=134.96, p<0.001\right.$ with an $R^{2}$ of 0.402$)$ and teamwork skills $\left(\mathrm{F}[1,201]=132.66, p<0.001\right.$ with an $R^{2}$ of 0.398 ) contributed the most, which followed by effectively running meetings $\left(\mathrm{F}[1,201]=105.65, p<0.001\right.$ with an $R^{2}$ of $0.34)$, and political advocacy $(F[1,201]=98.30, p<0.001$ with an $R^{2}$ of 0.33 ) for overall perceived effectiveness. All

Table 2 Means and standard deviations for leadership motivation

\begin{tabular}{|l|l|l|}
\hline Motivation & Mean & $\begin{array}{l}\text { Standard } \\
\text { deviation }\end{array}$ \\
\hline Seek more leadership responsibility & 4.52 & 0.66 \\
\hline Pursue a leadership position & 4.42 & 0.78 \\
\hline Spend time on leadership tasks & 4.49 & 0.69 \\
\hline Exercise leadership & 4.6 & 0.60 \\
\hline
\end{tabular}


Table $3 R^{2}$ values and means for Leadership Development Program workshops and overall effectiveness

\begin{tabular}{|l|l|l|}
\hline Workshop & $R^{2}$ values & Mean \\
\hline Negotiation & 0.215 & 4.0 \\
\hline Delegation & 0.288 & 3.96 \\
\hline Media relations & 0.204 & 4.19 \\
\hline Political advocacy & 0.328 & 4.5 \\
\hline Antitrust issues & 0.181 & 3.3 \\
\hline Run meeting & 0.345 & 4.16 \\
\hline Public speaking & 0.2 & 4.23 \\
\hline Networking & 0.402 & 4.42 \\
\hline Team work & 0.398 & 4.12 \\
\hline $\begin{array}{l}\text { Handle fiduciary } \\
\text { responsibilities }\end{array}$ & 0.228 & 3.60 \\
\hline $\begin{array}{l}\text { Communicated with } \\
\text { international colleagues }\end{array}$ & 0.234 & 3.88 \\
\hline
\end{tabular}

of the regression analyses were significant at $p$ $<0.001$. Table 3 shows the $R^{2}$ values for each of the workshop and its contribution to the perceived effectiveness of the LDP Program.

Regression analyses indicated that the overall development programs combined contributed significantly to participants' motivation to seek more leadership responsibility $\left(\mathrm{F}[11,191]=15.21, p<0.001\right.$ with an $R^{2}$ of 0.467$)$, spend time on leadership tasks $\left(\mathrm{F}[11,191]=14.65, p<0.001\right.$ with an $R^{2}$ of 0.458$)$, exercise leadership $(F[11,191]=14.98, p<0.001$ with an $R^{2}$ of 0.463$)$, and to a lesser extent pursue a leadership position after the program $(F[11,191]=5.16, p<0.001$ with an $R^{2}$ of 0.23 ).

To further determine the impact of AAO LDP on ophthalmic leadership, an in-depth retrospective monitoring of LDP graduates from the classes of 1999 to 2019 was performed. As of September 2020, it was found that on the national level, 268 of 383 LDP graduates (70.0\%) have served as AAO committee/task force members, AAO Councilors, or AAO representatives to outside organizations; 25 LDP graduates (6.5\%) have served either on the Board of Trustees or Committee of Secretaries. Two LDP graduates have served as AAO president, and one is the current (2022) AAO President. A total of 205 LDP graduates (53.5\%) have served as a state society president and 53 LDP graduates (13.8\%) have served as a subspecialty/specialized interest society president/chair. Furthermore, 16 LDP graduates $(4.2 \%)$ have served as president/chair of both a state and a subspecialty/specialized interest society.

\section{Discussion}

When established in 1998, the AAO LDP was the first leadership training program for ophthalmologists. There has been a paucity of peer-reviewed literature describing leadership and ophthalmology as well as a lack of evaluation for formalized LDPs catered specifically to ophthalmolo- gists. ${ }^{13}$ This is the first article that objectively evaluates the effectiveness of this AAO LDP. Additionally, to the authors' knowledge, this is the longest documented follow-up evaluation of any physician leadership program.

The primary objective of this study was to evaluate the effectiveness of the AAO LDP initiative by examining the perceptions and accomplishments of former program participants. This required testing the impact on our hypothesis that leadership training increases one's motivation to be a leader and one's confidence in one's own leadership skills. The data from this study support this hypothesis. However, it is important to underline that while we have measured the development of the participants' confidence in their own skills, our data cannot support a definitive statement that the participants' skills have improved. It would therefore not be surprising if our participants felt that leadership training had improved their leadership skills. Such feelings can, however, only be observed as an increase in one's confidence. It is possible that an individual would report an improvement in his or her leadership skills even if their skills, in reality, have not been improved because "people's behavior is based on their perception of what reality is, not on reality itself ${ }^{14}$. Increased confidence in one's own leadership skills can therefore be the result of improved skills and/or other factors. How former participants rate their experience and perceive their training as effective helps determine the program's overall effectiveness.

Retrospective monitoring of the 383 LDP graduates from the classes of 1999 to 2019 found many progressed to serve in leadership roles in their state society (54\%) and subspecialty/specialized interest society (14\%). Of those who served as leaders of both societies, there were more likely to be an LDP graduate than someone who had not participated in the program (16 vs. 12). Similarly, $70 \%$ of graduates stayed active within AAO to serve as AAO committee/task force members, AAO councilors, or AAO representatives to outside organizations. In total, 6.5\% have served at the highest levels of AAO board of trustees or committee of secretaries. Three LDP graduates have served as president of the AAO.

The authors recognize several limitations to this study. The survey design does not allow us to guarantee that the identified relations are causal. A related limitation was that we were asked to measure an impact without being empowered to secure variance in time. Further steps would be to consider an experimental pretest/post-test design going forward. There are also limitations to the interpretation of the retrospective monitoring of LDP alumni leadership positions. Many of the participants were ascended to these positions because they already were slated to be leaders of their nominating organization and thus put forward from their organizations for further training. Full efficacy of the AAO LDP may not be simply defined as the number of leadership positions attained after graduation, but on the program's impact on the quality of the leadership skills utilized and leadership performance demonstrated by its graduates, which was not assessed in this study. Furthermore, greater awareness of the LDP program (and a 


\section{Female Composition of AAO LDP and AAO Membership}

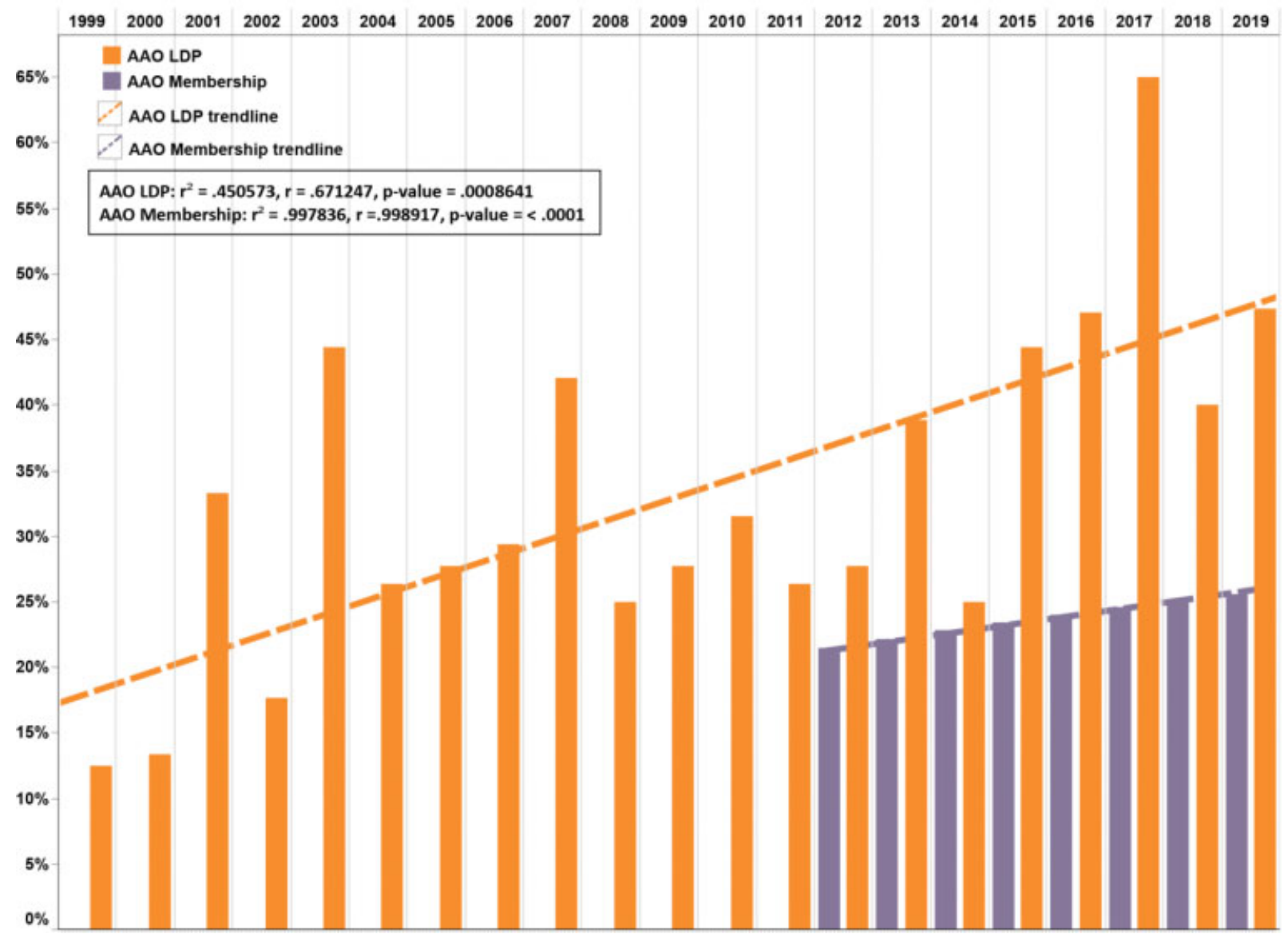

Fig. 1 Bar graph with overlying trendlines of female composition of AAO Leadership Development Program 1999-2019 compared with available AAO Female Membership Data. AAO, American Academy of Ophthalmology.

corresponding increase in applications) would ensure a larger and more diverse pool of candidates for selection based on leadership potential.

Another key goal of this study was to identify opportunities to improve future LDP programming. Utilizing the survey and data analysis, programming can be evaluated for effectiveness and to identify potential areas for improvement. Evaluation of our current programming suggests that putting more resources into the networking skills, running meetings and political advocacy items in the curriculum would have the greatest impact on the perceived overall effectiveness of the program. Programs with a mean below 4.0 can also improve on their effectiveness to improve participants' abilities. Given the particularly low rating for the fiduciary responsibility workshop, improving that workshop's ability to increase participants' effectiveness in that area would be valuable. Thus, the survey method and analysis put forward in this paper allows for not just evaluation purposes but monitoring and directing future adaptations of a leadership program.

Additional findings from this study has revealed, in comparing the available AAO membership survey data from 2012 to 2020 , there was a higher population of female participants enrolling in the LDP program than the general female population of AAO US membership ( - Fig. 1). In 2019, there was a higher female proportion of the LDP class compared with female proportion of both the U.S. practicing and trainee populations. Additionally, our results showed that women who participated in the AAO LDP program reported a greater improvement than men in skills training to work in teams and public speaking skills. These observations suggest that the AAO LDP program has supported female leaders and accelerated their training for leadership, thus playing a key role in contributing to improving gender equity in the field of ophthalmology. The importance of having physician leaders who reflect the demographics of our patients and our communities' needs cannot be overstated. Although the authors believe the AAO LDP program has encouraged improved diversity demographics besides gender over the years, improved self-identification of participants would help confirm that diversity, equity, and inclusion for our future generation of leaders is indeed being adequately addressed. Additional studies would be of value in validating the achievement of success in these areas.

AAO LDP has expanded over time to include the participation of international ophthalmologists and those graduates have established similar LDP programs that mirror the AAO LDP model. The LDP global community has been an 
unexpected, but important, result of the AAO LDP program. In the United States, a second generation of ophthalmology LDPs has been launched by and AAO LDP graduate or founder. Most recently, there has been the creation of the Association of University Professors of Ophthalmology LDP and the Association for Research in Vision and Ophthalmology Women's LDP. The launch of these new programs supports the benefits of the AAO LDP program model, as well as exemplifies the desire of AAO LDP graduates to continue in their leadership capacity and to create ways of mentoring others. However, studies to evaluate the effectiveness of this model and to direct programming are vital to creating the maximal benefit to the participants and the organizations that support them.

In summary, this retrospective analysis of the graduates of the AAO LDP supports the hypothesis that leadership training increases one's motivation to be a leader and one's confidence in one's own leadership skills. Through a survey of program alumni and identification of leadership positions filled by graduates, we have demonstrated that this program has achieved its goal to create leaders in the field of ophthalmology for the betterment of the field in pursuit of greater patient care.

\section{Funding}

This work was supported by an unrestricted grants from Research to Prevent Blindness to the J.F.H. MD Department of Ophthalmology and Visual Sciences at Washington University and the Department of Ophthalmology and Visual Sciences at Vanderbilt University Medical Center.

\section{Conflict of Interest}

None of the authors has any significant financial disclosures, however. Gail Schmidt is employed by the American Academy of Ophthalmology.

\section{Acknowledgments}

The authors would like to thanks Alexander Larsen, Dario Bodenmann, Juhee Suh, and Victor Monteiro (Haas School of Business, University of California, Berkeley, XB105 Project Class, 2020); Michael W. Brennan, MD (AAO LDP co-founder, Burlington, NC); Daniel J. Briceland, MD (previous LDP director, Carefree, AZ), David W. Johnson, MD (previous LDP director, Denver, CO), William R. Penland, MD (previous LDP director, Evansville, IN), and Aaron P. Weingeist, MD (previous LDP director- Seattle, WA); and Michael Levitt (data summary, American Academy of Ophthalmology, San Francisco, CA).

\section{References}

1 American Academy of Ophthalmology. 20200verview - American Academy of Ophthalmology. Accessed May 11, 2020 at: https://www.aao.org/about/who-we-are/overview

2 American Academy of Ophthalmology. 2020State societies. Accessed May 11, 2020 at: https://secure.aao.org/aao/Rosters/State-societies

3 Kirkpatrick D, Kirkpatrick J. Evaluating Training Programs: The Four Levels. 3rd ed. San Francisco, CA: Berrett-Koehler Publishers, Inc; 2006

4 Green C, Atik A, Hay M. Developing leadership skills in young ophthalmologists. Ann Eye Sci 2019;4:37

5 Klassen RM, Tze VM, Betts SM, Gordon KA. Teacher efficacy research 1998-2009: signs of progress or unfulfilled promise? Educ Psychol Rev 2011;23:21-43

6 Metso S, Kianto A. Vocational students' perspectives on professional skills workplace learning. J Workplace Learn 2014; 26:128-148

7 Petridou A, Nicolaidou M, Karagiorgi Y. Exploring the impact of professional development and professional practice on school leaders' self-efficacy: a quasi-experimental study. Sch Eff Sch Improv 2016;28:56-73

8 Bandura A. Social foundation of thought and action: a social cognitive theory. 1st ed. Englewood Cliffs, NJ: Prentice Hall; 1986

9 Stanjkovic AD, Luthans F. Self-efficacy and work-related performance: a meta-analysis. Psychol Bull 1998;124:240-261

10 Salanova M, Llorens S, Schaufeli WB. Yes, I can, I feel good, and I just do it! On gain cycles and spirals of efficacy beliefs, affect, and engagement. J Appl Psychol 2011;60:255-285

11 Bandura A. (1997). Self-Efficacy: The Exercise of Control. 1st ed. New York, NY: Worth; 1997

12 Demir $\mathrm{S}$. The role of self-efficacy in job satisfaction, organizational commitment, motivation and job involvement. Eur J Educ Res 2020;85:205-222

13 Berkowitz S, Law J, Sternberg P, Patel S. Leadership development in ophthalmology: survey of current opportunities and future needs. J Acad Ophthalmol 2021;13:32-39

14 Robbins S, Judge T. Organizational Behavior. 15th ed. New York, NY: Pearson; 2013 